\title{
Association between periodontitis and peripheral artery disease: a systematic review and meta-analysis
}

\author{
Shuo Yang ${ }^{\dagger}$, Li Sheng Zhao ${ }^{\dagger}$, Chuan Cai, Quan Shi, Ning Wen ${ }^{*}$ and Juan Xu ${ }^{*}$ (D)
}

\begin{abstract}
Background: Inflammation is a common feature of both peripheral arterial disease (PAD) and periodontitis. Some studies have evaluated the association between PAD and periodontitis. However, there is still no specialized meta-analysis that has quantitatively assessed the strength of the association. Thus, we conducted this meta-analysis to critically assess the strength of the association between PAD and periodontitis.

Methods: PubMed, Embase, and the Cochrane Library were searched for observational studies of the association between periodontitis and PAD in February 2018. Risk ratios (RRs) and their 95\% confidence intervals (Cls) from included studies were pooled to evaluate the strength of the association between periodontitis and PAD. Weighted mean differences (WMDs) and their 95\% Cls were pooled to compare the difference in periodontal-related parameters between PAD and non-PAD patients.

Results: Seven studies including a total of 4307 participants were included in the meta-analysis. The pooled analysis showed that there was a significant difference in the risk of periodontitis between PAD patients and non-PAD participants $(\mathrm{RR}=1.70,95 \% \mathrm{Cl}=1.25-2.29, P=0.01)$. There was also a significant difference in number of missing teeth between PAD patients and non-PAD participants (WMD $=3.75,95 \% \mathrm{Cl}=1.31-6.19, P=0.003)$. No significant difference was found in clinical attachment loss between PAD patients and non-PAD participants ( $\mathrm{WMD}=-0.05,95 \% \mathrm{Cl}=-0.03-0.19, P=0.686$ ).

Conclusion: In conclusion, the results of this meta-analysis revealed a significant relationship between periodontitis and PAD. Moreover, our study indicated that PAD patients had more missing teeth than control subjects did. Further high-quality and well-designed studies with specific inclusion and exclusion criteria are required to strengthen the conclusions of this study.
\end{abstract}

Keywords: Periodontitis, Peripheral arterial disease, Inflammation, Risk factor, Meta-analysis

\section{Background}

Periodontitis, a chronic inflammatory disease, is primarily characterized by the destruction of tooth-supporting tissues $[1,2]$. Without treatment, periodontitis typically causes a loss of connective tissue attachment, erosion of the alveolar bone and, ultimately, tooth loss [3]. In the US, nearly half of the population aged $>30$ years have periodontal problems, and nearly $10 \%$ of them have severe periodontitis [4]. The findings from current studies indicate that periodontitis is associated with a wide range of systemic diseases,

\footnotetext{
*Correspondence: wenningchn@163.com; newxj@hotmail.com 'Shuo Yang and Li Sheng Zhao contributed equally to this work. Department of Stomatology, Chinese People's Liberation Army General Hospital, 28 Fuxing Road, Beijing 100853, China
}

including pulmonary disease, diabetes mellitus, myocardial infarction, rheumatoid arthritis, and systemic lupus erythematosus [5-8]. The World Health Organization (WHO) has stated that oral health, including periodontal health, is an essential part of general health [9].

Higher levels of serum IL-6, C-reactive protein (CRP), TNF- $\alpha$ and IL- $1 \beta$ have been reported among periodontitis patients in several studies [10,11]. Additionally, the serum IL-6 and CRP levels have a positive association with the extent of periodontitis [12]. These results suggest that as a chronic inflammatory condition, periodontitis may contribute to increased serum inflammatory markers.

Peripheral artery disease (PAD), which is usually associated with atherosclerosis, results in a significant

(c) The Author(s). 2018 Open Access This article is distributed under the terms of the Creative Commons Attribution 4.0 International License (http://creativecommons.org/licenses/by/4.0/), which permits unrestricted use, distribution, and 
reduction of the lumen of peripheral arteries, and its most common symptom is intermittent claudication [13]. Studies have shown that PAD is associated with elevated morbidity and mortality with cardiovascular disease (CVD) $[14,15]$. The presence of PAD leads to a three- to six-fold increase in the risk of CVD mortality [16]. PAD shares the same underlying pathology as CVD and cerebrovascular diseases $[17,18]$. Systemic hyperinflammation plays an important role in the onset of these diseases. It has been reported that elevated circulating levels of IL-6, TNF- $\alpha$ and CRP are associated with the progression of CVD, PAD and cerebrovascular disease [19-21].

The relationship between periodontitis and CVD has been investigated in many studies, and there is strong evidence that periodontitis is associated with CVD [22-24], as PAD and CVD are both chronic infammatory conditions, and they share similar infammatory factors with periodontitis. We hypothesized that there may also exist an association between PAD and periodontitis. Mendez et al. [25] was the first to report that subjects with clinically significant periodontitis at baseline had a 2.27-fold possibility of developing PAD (OR $=2.27,95 \%$ $\mathrm{CI}=1.32-3.9)$. In a case-control study conducted by Soto-Barreras et al. [26], periodontitis, defined as a clinical attachment loss (CAL) $\geq 4 \mathrm{~mm}$ in at least $30 \%$ of the six measured sites, was strongly associated with PAD risk $(\mathrm{OR}=8.18,95 \% \mathrm{CI}=1.21-35.23)$. Similar findings have proliferated in recent years $[27,28]$. However, no specialized meta-analysis has quantitatively assessed the strength of the association between PAD and periodontitis. Thus, we conducted this meta-analysis to evaluate the possible association between PAD and periodontitis. The results of our study will expand the current knowledge of the etiology of PAD and will provide clinicians with better evidence-based recommendations and management strategies.

\section{Methods}

We conducted this meta-analysis in accordance with the Preferred Reporting Items for Systematic Reviews and Meta-Analyses statement (PRISMA) [29]. The checklist of the PRISMA guidelines has been put into the supplemental material (Additional file 1). This study was conducted according to the Population, Intervention, Control and Outcome (PICO) format, in order to answer the following focused PICO question:

Are people (P) with periodontitis (I) more likely to get $\operatorname{PAD}(\mathrm{O})$ ?

Population: humans with or without PAD

Intervention: participants with periodontitis

Comparison: non-PAD participants with periodontitis

Outcome: PAD

\section{Literature-search strategy}

We performed a literature search in February 2018, and the search language was restricted to English. PubMed, Embase, and the Cochrane Library were searched using the following key words: "periodontitis," "periodontal disease," "peripheral vascular disease," and "peripheral arterial disease." In addition, we identified additional studies by checking the reference lists of the related studies. The search strategy (Additional file 2) has been put into the supplemental material.

\section{Inclusion and exclusion criteria}

We included studies that (1) reported the relationship between periodontitis and risk of PAD; (2) defined PAD by ankle brachial pressure index (ABI) or angiographic findings or clinical symptoms [30]; (3) defined periodontitis using at least one of several clinical definitions according to the International Workshop for the Classification of Periodontal Disease [31] or by self-report using questionnaires or clinical diagnosis by a periodontist; (4) were observational, including those with a cross-sectional, case-control, or cohort design; and (5) had data that could be extracted.

The exclusion criteria were (1) animal model or in vitro studies; (2) reviews, case reports or comments; (3) non-English-language studies; and (4) studies without available data.

\section{Study selection methods}

To select studies, we first excluded duplicated studies from the literature search. Then, we screened the titles and abstracts and excluded obviously irrelevant studies. After assessing the full texts of potentially eligible studies, we only included studies that met the inclusion criteria. The entire process was conducted by 2 reviewers, and any disagreements were resolved by discussion with a third reviewer.

\section{Data extraction and quality assessment}

Two authors (SY and LSZ) independently assessed the characteristics of included studies. The following information was extracted from each included study: first author's name and year of publication; country of study; study design; characteristics of the study participants, including number of patients and controls, age range, and sex; study population; definition of PAD and periodontitis; and adjusted or matched factors.

The Newcastle-Ottawa Scale (NOS) [32] was used by two authors (CC and QS) to complete the quality assessment of all eligible studies. The NOS ratings (Additional file 3) has been put into the supplemental material. In this assessment tool, study selection, comparability, and outcome were used to appraise the methodological quality of the included studies, with a maximum of 
9 points for each study. NOS scores of 1-3, 4-6, and 7-9 indicated low, moderate, and high study quality, respectively.

\section{Statistical analysis}

Statistical analyses were performed using the Stata 12.0 software (Stata Corporation, College Station, TX, USA). The risk ratios (RRs) and 95\% confidence intervals (CIs) from the included studies were pooled to evaluate the strength of the association between periodontitis and PAD. As the parameters used for evaluating periodontal status were continuous variables, weighted mean differences and their $95 \%$ CIs were pooled to compare the difference in periodontal status between PAD and non-PAD patients.

The $\mathrm{I}^{2}$ statistic was used to assess the degree of heterogeneity among studies. The values 25,50 , and $75 \%$ corresponded to low, moderate, and high heterogeneity, respectively. A fixed effects model was applied if $\mathrm{I}^{2}<50 \%$, and a random effects model was used if $\mathrm{I}^{2}>50 \%$.

\section{Results}

\section{Literature selection}

The detailed literature selection process is shown in Fig. 1. Based on the search strategy, 273 potentially relevant studies were selected from the electronic database. Of these studies, 140 were excluded after removing duplicates. After screening titles and abstracts, 119 irrelevant studies were excluded because they failed to meet the eligibility criteria. Twelve studies were subsequently assessed by full text review, and 5 studies were removed for various reasons. Ultimately, 7 studies were included in our meta-analysis [25-28, 30, 33, 34].

\section{Study characteristics}

The characteristics of the included studies are shown in Tables 1 and 2. A total of 4307 participants were included in the meta-analysis, for a total of 493 participants with PAD and 3814 participants without PAD. The publication dates of the included studies ranged from 1998 to 2017. Of the seven included studies, four $[26,27,30,33]$ were case-control studies, two $[28,34]$ were cross-sectional studies, and one [25] was a prospective cohort study. Three studies [27, 28, 30] were conducted in Asian countries, two studies $[25,26]$ were conducted in American countries, and two [33, 34] were conducted in European countries. One study [25] enrolled male participants only, and one [33] enrolled female participants only.

The quality of the included studies was assessed using the NOS; the results are shown in Table 2. Four case-control studies [26, 27, 30, 33] and one cohort study [25] scored more than 6 points and were considered to be of high quality. Two cross-sectional studies $[28,34]$ scored 6 points and were considered to be of moderate quality.

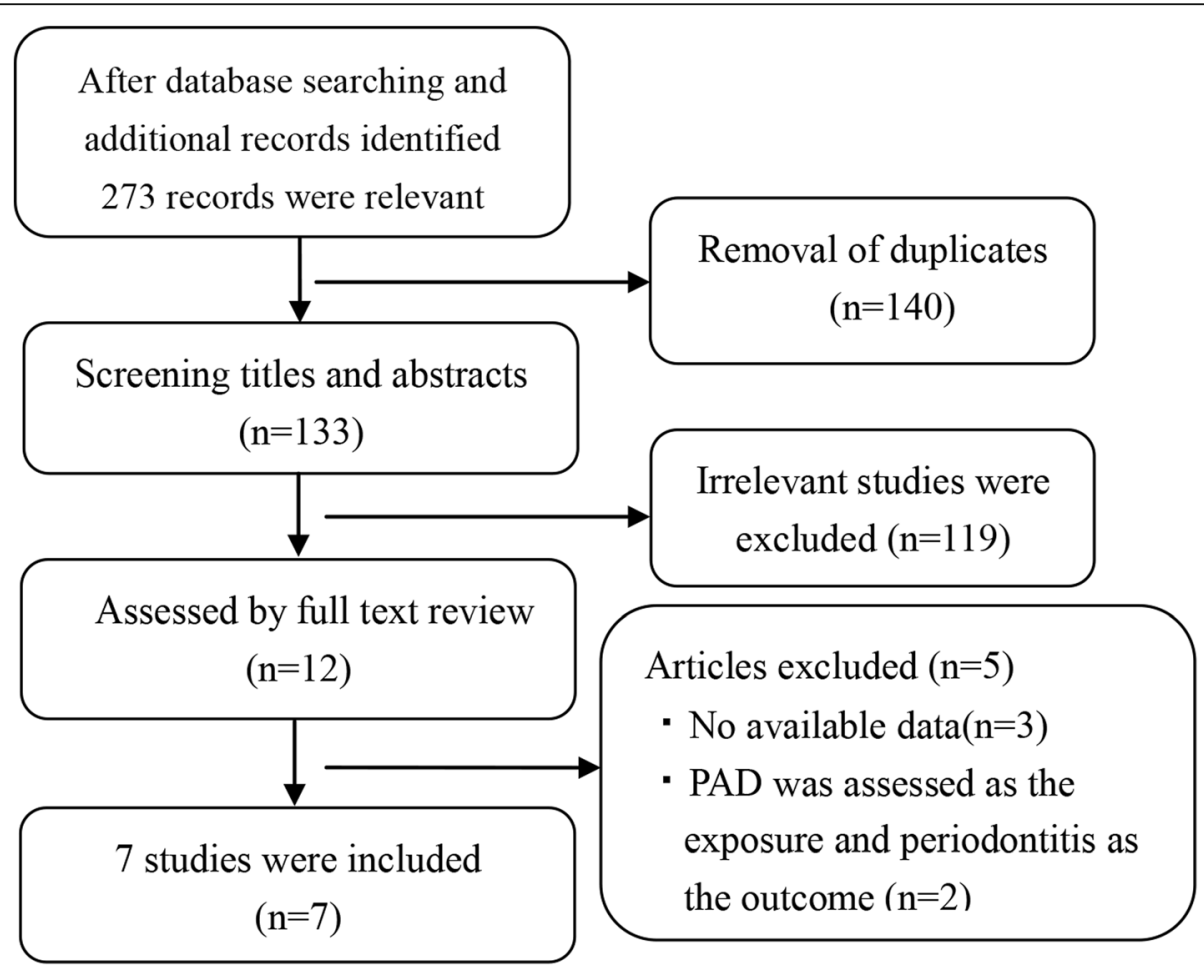

Fig. 1 Study flow diagram 
Table 1 Characteristics of included studies

\begin{tabular}{|c|c|c|c|c|c|c|c|}
\hline \multirow[t]{2}{*}{ Study (Author, Year) } & \multirow[t]{2}{*}{ Country } & \multirow{2}{*}{$\begin{array}{l}\text { Study } \\
\text { population }\end{array}$} & \multirow[t]{2}{*}{ Study Design } & \multicolumn{2}{|l|}{ PAD ${ }^{a}$ patients } & \multicolumn{2}{|l|}{ Control } \\
\hline & & & & $\begin{array}{l}\text { Number (M/ } \\
\text { F) }\end{array}$ & $\begin{array}{l}\text { Age }\left(S D^{C} \text { or }\right. \\
\text { Range) }\end{array}$ & Number (M/F) & $\begin{array}{l}\text { Age (SD or } \\
\text { Range) }\end{array}$ \\
\hline Aoyama et al. 2017 [22] & Japan & hospital-based & $\begin{array}{l}\text { cross- } \\
\text { sectional }\end{array}$ & $34(23 / 11)$ & $65.6 \pm 11.8$ & $956(693 / 263)$ & $64.4 \pm 13.0$ \\
\hline Çalapkorur et al. 2017 [34] & Turkey & hospital-based & $\begin{array}{l}\text { cross- } \\
\text { sectional }\end{array}$ & $40(32 / 8)$ & $60.45 \pm 9.94$ & $20(18 / 2)$ & $57.40 \pm 11.16$ \\
\hline Ahn et al. 2016 [27] & $\begin{array}{l}\text { South } \\
\text { Korea }\end{array}$ & $\begin{array}{l}\text { population- } \\
\text { based }\end{array}$ & case-control & $72(28 / 44)$ & $N R^{d}$ & $\begin{array}{l}\text { 1271 (473/ } \\
798)\end{array}$ & NR \\
\hline Soto-Barreras et al. 2013 [26] & Mexico & hospital-based & case-control & $30(8 / 22)$ & $61.86 \pm 8.49$ & $30(9: 21)$ & $63.23 \pm 9.06$ \\
\hline Chen et al. 2008 [30] & Japan & hospital-based & case-control & $25(21 / 4)$ & $67.6 \pm 10$ & $32(28 / 4)$ & $63.1 \pm 10$ \\
\hline $\begin{array}{l}\text { Bloemenkamp et al. } 2002 \\
\text { [33] }\end{array}$ & Netherlands & $\begin{array}{l}\text { population- } \\
\text { based }\end{array}$ & case-control & $212(0 / 212)$ & $48.2 \pm 7.0$ & $475(0 / 475)$ & $45.5 \pm 8.1$ \\
\hline Mendez et al. 1998 [25] & USA & $\begin{array}{l}\text { population- } \\
\text { based }\end{array}$ & cohort & $80(80 / 0)$ & $44.2(29-62)$ & $1030(1030 / 0)$ & $42.7(23-80)$ \\
\hline
\end{tabular}

${ }^{\text {aPAD, peripheral arterial disease }}$

${ }^{\mathrm{b}} \mathrm{M} / \mathrm{F}$, male/female

'SD, standard deviation

${ }^{\mathrm{d}} \mathrm{NR}$, not report

Table $\mathbf{2}$ Characteristics of included studies

\begin{tabular}{|c|c|c|c|c|}
\hline $\begin{array}{l}\text { Study (Author, } \\
\text { Year) }\end{array}$ & Defnition of PAD & Defnition of periodontitis & $\begin{array}{l}\text { Adjusted or matched } \\
\text { factors }\end{array}$ & $\begin{array}{l}\text { NOS } \\
\text { score }\end{array}$ \\
\hline $\begin{array}{l}\text { Aoyama et al. } \\
2017 \text { [22] }\end{array}$ & $\begin{array}{l}\text { PAD was diagnosed based on clinical symptoms, } \\
A B I \text {, and angiographic fndings }\end{array}$ & NR & $\begin{array}{l}\text { age, sex, smoking, } \\
\text { hypertension, } \\
\text { dyslipidemia and } \\
\text { HbA1c levels }\end{array}$ & 6 \\
\hline
\end{tabular}

Calapkorur et Patients with $A B \mid$ values of $\leq 0.90$ were

al. 2017 [34] diagnosed as having PAD

Ahn et al. PAD was evaluated by using ABI lower than 1.0

2016 [27]

Soto-Barreras Patients with $A B I$ values of $\leq 0.90$ were

et al. 2013 [26] diagnosed as having PAD

Chen et al. PAD was diagnosed based on clinical symptoms, $2008[30]$ $A B I$, and angiographic fndings

Bloemenkamp PAD was angiographically confirmed when a et al. 2002 [33] stenotic lesion causing more than 50\% reduction of the lumen was present in at least one major peripheral artery

Mendez et al. PAD was defined as one or more of the 1998 [25] following: (1) intermittent claudication; (2) extracranial erebrovascular disease; (3) atherosclerosis (including aortic, renal, and mesenteric disease); and (4) arterial embolism and thrombosis.
Periodontitis was defined as the presence of at least five teeth with one or more sites with a PD of $\geq 5 \mathrm{~mm}$, a CAL of $\geq 2 \mathrm{~mm}$, the presence of BOP and $30 \%$ radiographic bone loss

The radiographic alveolar bone loss $4 \mathrm{~mm}$ at two or more interproximal sites, not on the same tooth

age, gender, diabetes, 6 hypertension and $\mathrm{BMI}$

age, sex, education 7

level, tooth loss, smoking, drinking, central obesity

The diagnosis of periodontitis was determined when the attachment loss was $\geq 4 \mathrm{~mm}$ in $\geq 30 \%$ of measured sites.

Participants who presented with at least one probing site with PD $4 \mathrm{~mm}$ or CAL $4 \mathrm{~mm}$ in each quadrant were defined as periodontitis patients

NR

age, sex, BMI,smoking, 8 and diabetes mellitus

Smoking, age, gender, 7 and diabetes

Smoking, age, gender, 7 and diabetes

Periodontitis was considered present if the mean age, BMI, family history 8 whole mouth alveolar bone loss was $>20 \%$. of heart disease, and smoking exposure 


\section{Meta-analysis}

\section{$P A D$ and periodontitis prevalence}

Six studies [25-27, 30, 33, 34] that had available data to calculate the RRs and $95 \%$ CIs were included in the meta-analysis to evaluate the strength of the association between PAD and periodontitis. The pooled analysis indicated a significant difference in the risk of periodontitis between PAD patients and non-PAD participants $(\mathrm{RR}=1.70,95 \% \mathrm{CI}=1.25-2.29, \quad P=0.01$, Fig. 2). However, considering the high heterogeneity $\left(\mathrm{I}^{2}=78.3 \%\right)$ of the included studies, a random effects model was used.

\section{Missing teeth}

Three studies [26-28] compared the number of missing teeth in PAD patients and non-PAD participants. The meta-analysis showed that PAD patients lost more teeth than non-PAD participants did, and the difference was statistically significant $(\mathrm{WMD}=3.75,95 \% \quad \mathrm{CI}=1.31-$ $6.19, P=0.003$, Fig. 3). Considering the high heterogeneity $\left(\mathrm{I}^{2}=56.9 \%\right)$ of the included studies, a random effects models was used.

\section{Clinical attachment loss (CAL)}

Two studies [28, 34] reported CAL results in PAD patients and non-PAD participants. The pooled analysis showed that there was no significant difference in clinical attachment loss between PAD patients and non-PAD participants (WMD $=-0.05,95 \% \mathrm{CI}=-0.03-$ $0.19, P=0.686$, Fig. 4). Considering the low heterogeneity $\left(\mathrm{I}^{2}=0.0 \%\right)$ of the included studies, a fixed effects model was used.

\section{Discussion}

In this meta-analysis, we found a statistically significant increased risk of periodontitis in PAD patients compared to non-PAD participants, suggesting that there was a significant association between PAD and periodontitis. Moreover, we found that PAD patients had more missing teeth than non-PAD participants did. However, there was no statistical difference in CAL between PAD patients and controls.

Our finding that periodontitis was associated with PAD is in agreement with other studies focused on this relationship. Ahn et al. [27] reported that periodontitis was a risk factor for PAD; their study showed that patients with periodontitis had a 2.03-fold increase in the risk of PAD (95\% CI $=1.05-$ 3.93). Çalapkorur et al. [34] showed that periodontitis raised the odds ratio for developing PAD to 5.84 (95\% CI $=1.56-21.91)$. Chen et al. [30] conducted a case-control study and found that periodontitis was associated with a relative risk of 5.45 (95\% CI $=1.57-$ 18.89) for developing PAD.

In this meta-analysis, we also compared periodontal parameters, such as the CAL and number of missing teeth, to reflect the periodontal status of PAD patients and non-PAD participants. CAL is well known as a gold-standard measurement for periodontitis in both clinical research and clinical work [35]. However, this meta-analysis failed to find a difference in CAL between PAD patients and non-PAD participants. This null finding may have been caused by the heterogeneity of the study groups and the limited number of related studies. Hence, further well-designed studies are needed to evaluate this relationship.

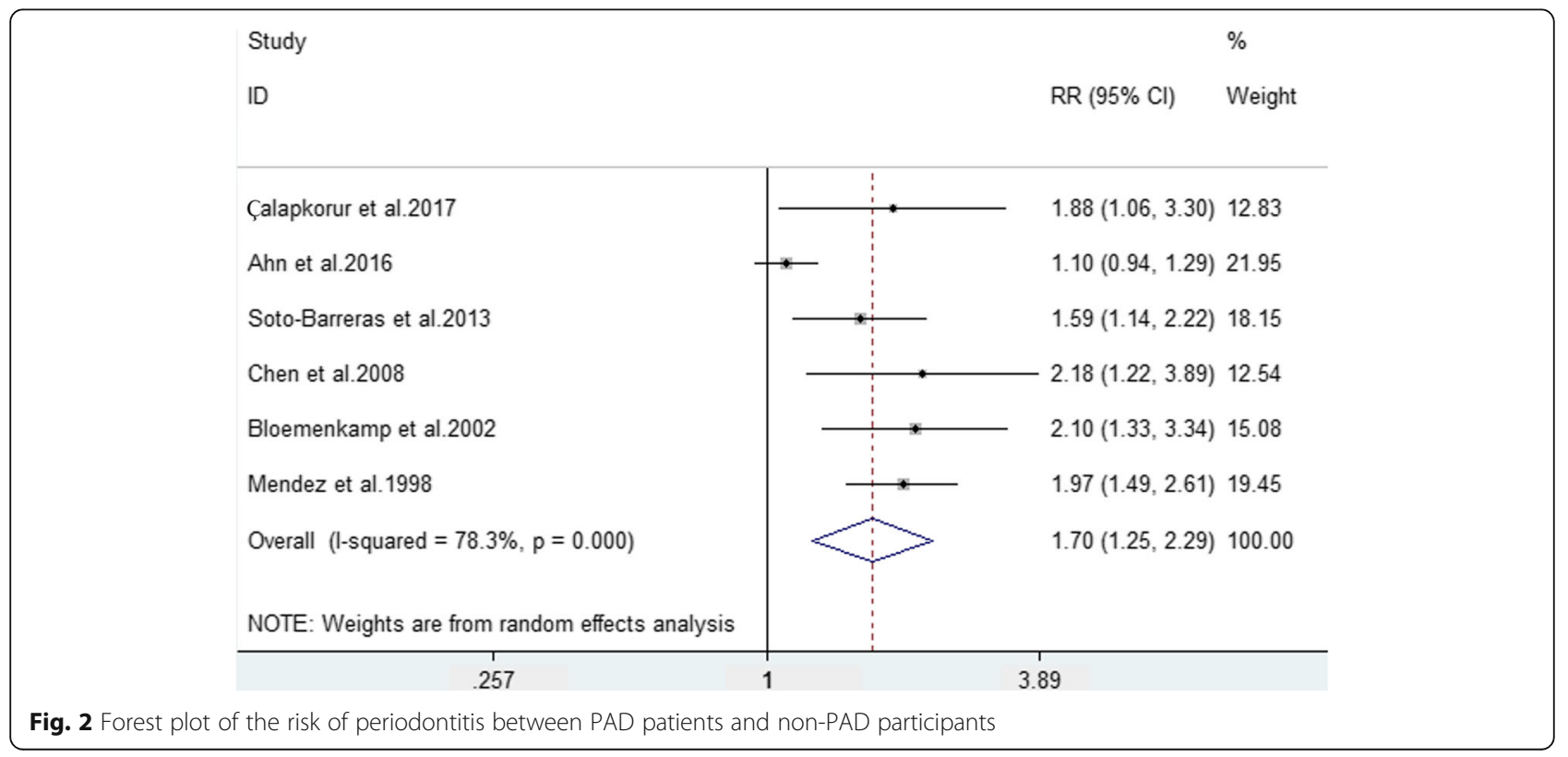




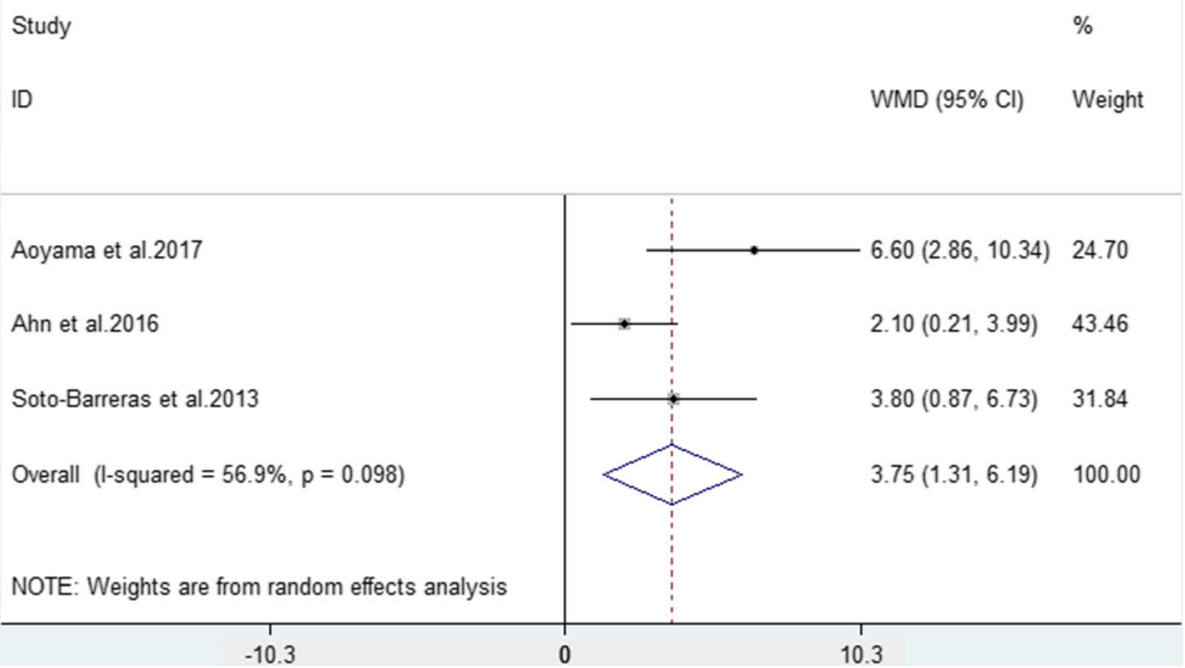

Fig. 3 Forest plot of the weighted mean difference in missing teeth between PAD patients and non-PAD participants

Missing teeth can reflect an irreversible condition in the end-stage of periodontitis [36]. Our meta-analysis indicated that PAD patients typically have more missing teeth than non-PAD participants do. It is well known that the most important cause of missing teeth is periodontitis. This result, in turn, may illustrate the close relationship between periodontitis and PAD.

The mechanism by which periodontitis causes PAD is not yet fully understood. However, elevated levels of inflammatory mediators such as IL-6, IL- $1 \beta$ and TNF- $\alpha$ in systemic circulation within PAD patients suggests that chronic infection in the body that may play an important role [11, 30, 37]. Periodontitis is a chronic inflammatory disease, and it is believed that periodontitis has the ability to induce local and host immune responses and to cause both transient bacteremia and the release of inflammatory mediators such as ILs and TNF- $\alpha$. These mediators can subsequently damage endothelial tissues and eventually lead to PAD [11, 38].

However, we observed high heterogeneity among the studies included in the meta-analysis. The observed heterogeneity may have been due to several factors. First, diagnostic criteria and methods of evaluating periodontitis were different among the included studies, and in some studies, the methods were not reported. These different criteria and evaluation methods for periodontitis lead to variation in the outcome measures and thus cause heterogeneity.

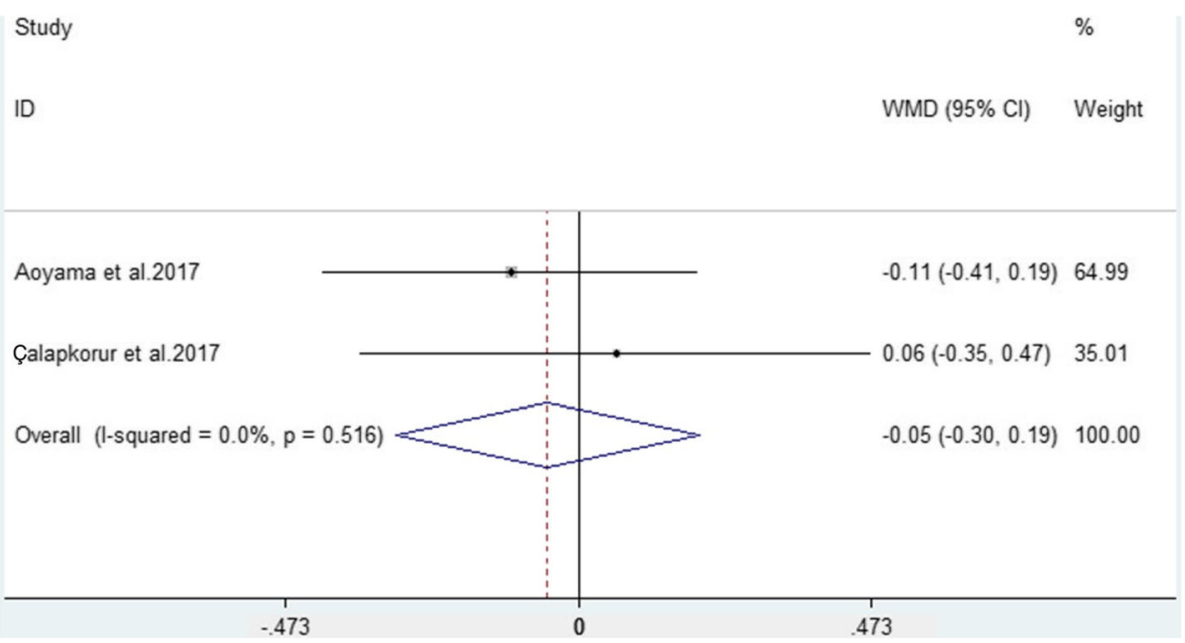

Fig. 4 Forest plot of the weighted mean difference in CAL between PAD patients and non-PAD participants 
Second, different types of observational studies and study populations were included in this study. We included cross-sectional, case-control, and cohort studies in this meta-analysis, and the hospital-based or population-based subjects were recruited in different studies. Third, different adjustments for confounding factors may play a role in heterogeneity. Some factors can affect both PAD and periodontitis independently, such as diabetes, tobacco and age. Moreover, unmeasured confounders may exist and could lead to heterogeneity. Fourth, the limited patient numbers in some studies may have contributed to the inconsistent results and resulted in high heterogeneity.

To our knowledge, this is the first meta-analysis to estimate the association between periodontitis and PAD. Our results showed a significant relationship between periodontitis and PAD. Additionally, our study indicated that PAD patients had more missing teeth than control subjects did. Furthermore, a study conducted by Blum et al. [39] found that treating periodontitis effectively improved the function of the vascular endothelium and may play a protective role in vascular injury and prevent PAD. From the perspective of public health, periodontitis is a disease that can be prevented and treated; thus, the effective implementation of prevention programs and treatment measures could not only improve oral health but may also reduce the risk of PAD. It should be noted that the current evidence only reveals a potential association of periodontitis and PAD. The specific mechanisms by which the two diseases are associated remain unknown, and further experimental studies to investigate pathologic mechanisms underlying periodontitis and PAD are needed.

The current meta-analysis has some limitations. First, high heterogeneity among the included studies was detected during analysis. Second, sensitivity analysis, meta-regression, and publication bias analyses were not performed due to the limited number of included studies. Third, the included studies were published in English; thus, relevant studies published in other languages may have been overlooked, causing selection bias.

\section{Conclusions}

In conclusion, the results of this meta-analysis revealed a significant relationship between periodontitis and PAD. Moreover, our study demonstrated that PAD patients had more missing teeth than control subjects did. However, the results should be viewed with caution because of the high heterogeneity and limited number of included studies. Further high-quality and well-designed studies with specific inclusion and exclusion criteria are required to strengthen the conclusions of this study.

\section{Additional files}

Additional file 1: The checklist of PRISMA guidelines. (DOC $64 \mathrm{~kb}$ )

Additional file 2: Table S1. Search strategy. (PDF $11 \mathrm{~kb}$ )

Additional file 3: NOS ratings. (PDF $17 \mathrm{~kb}$ )

\section{Abbreviations}

ABI: Ankle brachial pressure index; CAL: Clinical attachment loss; Cls: Confidence intervals; CRP: C-reactive protein; CVD: Cardiovascular disease; NOS: Newcastle-Ottawa Scale; PAD: Peripheral arterial disease;

PRISMA: Preferred Reporting Items for Systematic Reviews and Meta-Analyses statement; RRs: Risk ratios; WHO: World health organization;

WMDs: Weighted mean differences

\section{Acknowledgements}

Not applicable.

\section{Funding}

This study was supported by grant from the National Natural Science Foundation of China (No.51472270).

\section{Availability of data and materials}

All data generated or analysed during this study are included in this published article and its Additional files.

\section{Authors' contributions}

SY and LSZ carried out the literature research and drafted the manuscript. LSZ, CC and QS completed the data extraction and performed the statistical analysis. NW and JX are the corresponding author, and they designed this meta-analysis and helped to draft the manuscript. All authors read and approved the final manuscript.

Ethics approval and consent to participate

Not applicable.

Consent for publication

Not applicable.

Competing interests

The authors declare that they have no competing interests.

\section{Publisher's Note}

Springer Nature remains neutral with regard to jurisdictional claims in published maps and institutional affiliations.

Received: 15 March 2018 Accepted: 2 July 2018

Published online: 06 July 2018

\section{References}

1. Lundmark A, Davanian H, Bage T, Johannsen G, Koro C, Lundeberg J, et al. Transcriptome analysis reveals mucin 4 to be highly associated with periodontitis and identifies pleckstrin as a link to systemic diseases. Sci Rep. 2015;5:18475.

2. Williams RC. Periodontal disease. N Engl J Med. 1990;322(6):373-82.

3. Pihlstrom BL, Michalowicz BS, Johnson NW. Periodontal diseases. Lancet (London, England). 2005:366(9499):1809-20.

4. Eke PI, Zhang X, Lu H, Wei L, Thornton-Evans G, Greenlund K, et al. Predicting periodontitis at state and local levels in the United States. J Dent Res. 2016;95(5):515-22

5. Rutter-Locher Z, Smith TO, Giles I, Sofat N. Association between systemic lupus erythematosus and periodontitis: a systematic review and metaanalysis. Front Immunol. 2017;8:1295.

6. Hobbins S, Chapple IL, Sapey E, Stockley RA. Is periodontitis a comorbidity of COPD or can associations be explained by shared risk factors/behaviors? IntJ Chron Obstruct Pulmon Dis. 2017;12:1339-49.

7. Shi Q, Zhang B, Huo N, Cai C, Liu H, Xu J. Association between myocardial infarction and periodontitis: a meta-analysis of case-control studies. Front Physiol. 2016;7:519. 
8. Cardoso EM, Reis C, Manzanares-Cespedes MC. Chronic periodontitis, inflammatory cytokines, and interrelationship with other chronic diseases. Postgrad Med. 2018;130(1):98-104.

9. Petersen PE, Kwan S. The 7th WHO global conference on health promotion: towards integration of oral health (Nairobi, Kenya, 2009). Community Dent Health. 2010;27(Suppl 1):1-9.

10. Ebersole JL, Machen RL, Steffen MJ, Willmann DE. Systemic acute-phase reactants, C-reactive protein and haptoglobin, in adult periodontitis. Clin Exp Immunol. 1997;107(2):347-52

11. Gorska R, Gregorek H, Kowalski J, Laskus-Perendyk A, Syczewska M, Madalinski K. Relationship between clinical parameters and cytokine profiles in inflamed gingival tissue and serum samples from patients with chronic periodontitis. J Clin Periodontol. 2003;30(12):1046-52.

12. Loos BG, Craandijk J, Hoek FJ, Wertheim-van Dillen PM, van der Velden U. Elevation of systemic markers related to cardiovascular diseases in the peripheral blood of periodontitis patients. J Periodontol. 2000;71(10):1528-34

13. Ouma GO, Jonas RA, Usman MH, Mohler ER 3rd. Targets and delivery methods for therapeutic angiogenesis in peripheral artery disease. Vasc Med (London, England). 2012;17(3):174-92.

14. Howell MA, Colgan MP, Seeger RW, Ramsey DE, Sumner DS. Relationship of severity of lower limb peripheral vascular disease to mortality and morbidity: a six-year follow-up study. J Vasc Surg. 1989;9(5):691-6. discussion 696-697

15. McKenna M, Wolfson S, Kuller L. The ratio of ankle and arm arterial pressure as an independent predictor of mortality. Atherosclerosis. 1991; 87(2-3):119-28

16. Hirsch AT, Criqui MH, Treat-Jacobson D, Regensteiner JG, Creager MA, Olin JW, et al. Peripheral arterial disease detection, awareness, and treatment in primary care. JAMA. 2001;286(11):1317-24.

17. Blaizot A, Vergnes JN, Nuwwareh S, Amar J, Sixou M. Periodontal diseases and cardiovascular events: meta-analysis of observational studies. Int Dent J. 2009:59(4):197-209.

18. Sfyroeras GS, Roussas N, Saleptsis VG, Argyriou C, Giannoukas AD. Association between periodontal disease and stroke. J Vasc Surg. 2012; 55(4):1178-84

19. Botti C, Maione C, Dogliotti G, Russo P, Signoriello G, Molinari AM, et al. Circulating cytokines present in the serum of peripheral arterial disease patients induce endothelial dysfunction. J Biol Regul Homeost Agents. 2012; 26(1):67-79.

20. Moreno VP, Subira D, Meseguer E, Llamas P. IL-6 as a biomarker of ischemic cerebrovascular disease. Biomark Med. 2008;2(2):125-36.

21. Kofler S, Nickel T, Weis M. Role of cytokines in cardiovascular diseases: a focus on endothelial responses to inflammation. Clini Sci (London). 2005; 108(3):205-13.

22. Aoyama N, Suzuki Jl, Kobayashi N, Hanatani T, Ashigaki N, Yoshida A, et al. Associations among tooth loss, systemic inflammation and antibody titers to periodontal pathogens in Japanese patients with cardiovascular disease. J Periodontal Res. 2018;53(1):117-22.

23. Li C, LV Z, Shi Z, Zhu Y, Wu Y, Li L, et al. Periodontal therapy for the management of cardiovascular disease in patients with chronic periodontitis. Cochrane Database Syst Rev. 2017;11:Cd009197.

24. Almeida A, Fagundes NCF, Maia LC, Lima RR. Is there an association between periodontitis and atherosclerosis in adults? A systematic review. Curr Vasc Pharmacol. 2017. https://doi.org/10.2174/ 1570161115666170830141852 . Epub ahead of print.

25. Mendez MV, Scott T, LaMorte W, Vokonas P, Menzoian JO, Garcia R. An association between periodontal disease and peripheral vascular disease. Am J Surg. 1998;176(2):153-7

26. Soto-Barreras U, Olvera-Rubio JO, Loyola-Rodriguez JP, Reyes-Macias JF, Martinez-Martinez RE, Patino-Marin N, et al. Peripheral arterial disease associated with caries and periodontal disease. J Periodontol. 2013; 84(4):486-94

27. Ahn YB, Shin MS, Han DH, Sukhbaatar M, Kim MS, Shin HS, et al. Periodontitis is associated with the risk of subclinical atherosclerosis and peripheral arterial disease in Korean adults. Atherosclerosis. 2016;251:311-8.

28. Aoyama N, Suzuki Jl, Kobayashi N, Hanatani T, Ashigaki N, Yoshida A, et al. Periodontitis deteriorates peripheral arterial disease in Japanese population via enhanced systemic inflammation. Heart Vessel. 2017:32(11):1314-9.

29. Liberati A, Altman DG, Tetzlaff J, Mulrow C, Gotzsche PC, loannidis JP, et al. The PRISMA statement for reporting systematic reviews and meta-analyses of studies that evaluate healthcare interventions: explanation and elaboration. BMJ (Clinical research ed). 2009:339:b2700.

30. Chen YW, Umeda M, Nagasawa T, Takeuchi Y, Huang Y, Inoue Y, et al. Periodontitis may increase the risk of peripheral arterial disease. Eur J Vasc Endovasc Surg. 2008;35(2):153-8.

31. Armitage GC. Development of a classification system for periodontal diseases and conditions. Northwest Dent. 2000;79(6):31-5.

32. Wells GA, Shea B, O'Connell D, Peterson J, Welch V, Losos M, Tugwell P. The Newcastle-Ottawa Scale (NOS) for assessing the quality of nonrandomised studies in meta-a nalyses. In: Clinical epidemiology The Ottawa Hospital. 2018. http://www.ohri.ca/programs/clinical_epidemiology/oxford.ASp. Accessed 3 Mar 2018.

33. Bloemenkamp DG, van den Bosch MA, Mali WP, Tanis BC, Rosendaal FR, Kemmeren JM, et al. Novel risk factors for peripheral arterial disease in young women. Am J Med. 2002;113(6):462-7.

34. Calapkorur MU, Alkan BA, Tasdemir Z, Akcali Y, Saatci E. Association of peripheral arterial disease with periodontal disease: analysis of inflammatory cytokines and an acute phase protein in gingival crevicular fluid and serum. J Periodontal Res. 2017;52(3):532-9.

35. Savage A, Eaton KA, Moles DR, Needleman I. A systematic review of definitions of periodontitis and methods that have been used to identify this disease. J Clin Periodontol. 2009:36(6):458-67.

36. Hyde S, Dupuis V, Mariri BP, Dartevelle S. Prevention of tooth loss and dental pain for reducing the global burden of oral diseases. Int Dent J. 2017;67(Suppl 2):19-25.

37. Dye BA, Choudhary K, Shea S, Papapanou PN. Serum antibodies to periodontal pathogens and markers of systemic inflammation. J Clin Periodontol. 2005;32(12):1189-99.

38. Jimenez M, Krall EA, Garcia RI, Vokonas PS, Dietrich T. Periodontitis and incidence of cerebrovascular disease in men. Ann Neurol. 2009;66(4):505-12

39. Blum A, Kryuger K, Mashiach Eizenberg M, Tatour S, Vigder F, Laster Z, et al. Periodontal care may improve endothelial function. Eur J Intern Med. 2007; 18(4):295-8

Ready to submit your research? Choose BMC and benefit from

- fast, convenient online submission

- thorough peer review by experienced researchers in your field

- rapid publication on acceptance

- support for research data, including large and complex data types

- gold Open Access which fosters wider collaboration and increased citations

- maximum visibility for your research: over $100 \mathrm{M}$ website views per year

At BMC, research is always in progress.

Learn more biomedcentral.com/submissions 